\title{
OBITUARIO
}

\section{ELÍAS RAMÓN DE LA SOTA}

(1932-2014)

\section{Pedes in terra ad sidera visus}

El 21 de enero de 2014, a las 12.30 am, el Dr. Elías Ramón de la Sota, o Cacho como le decían las personas más allegadas, dejó de estar físicamente con nosotros para radicarse en nuestra memoria. Nacido en la ciudad de Tucumán, el 27 de septiembre de 1932, completó su primera etapa de formación botánica en esa ciudad.

Sus estudios de grado los realizó en la Escuela Universitaria de Ciencias Naturales e Instituto Miguel Lillo, periodo en el cual también se desempeñó

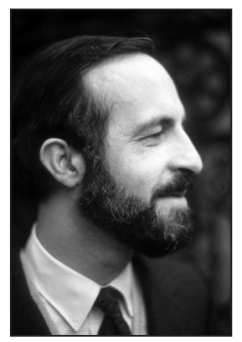
como auxiliar docente en la Cátedra de Botánica y técnico de la biblioteca de esa misma casa de estudios.

Su doctorado lo efectuó también en el Instituto Miguel Lillo, bajo la dirección del Dr. Rolf Singer. Es destacable el hecho de que su doctorado lo realizó prácticamente de noche, ya que durante el día debía cumplir con sus obligaciones laborales de bibliotecario. Su tesis doctoral fue la primera en obtener la orientación en botánica, la cual se tituló "Polypodiaceae y Grammitidaceae Argentinas". Su presentación fue calificada como sobresaliente "suma cum laude", siendo así recomendada para su publicación ${ }^{1}$.

Después de concluir una beca de investigación en Brasil, se hace cargo de la Cátedra de Morfología Vegetal en la Facultad de Ciencias Naturales y Museo de La Plata en septiembre de 1962.

En el año de 1963 concretó una estadía de un año en el Departamento de Botánica de Ann Arbor, en la Universidad de Michigan mediante una beca de la John Simon Guggenheim Memorial Foundation. Posteriormente emprende varios viajes de recolección de especímenes botánicos por distintas partes de Centro América y América del Sur, éstos estuvieron patrocinados por distintas instituciones extranjeras. Un juego de estas importantes colecciones se encuentra depositado en el herbario del Museo de Ciencias Naturales de La Plata (LP).

Al establecerse en La Plata como docente, trató de estimular los estudios en helechos y licófitas, conformando un grupo de discípulos distribuidos en diferentes partes del país. Esta predisposición por compartir sus conocimientos se evidencia en su participación como director de 14 tesis doctorales. Su incansable labor como orientador de investigadores y alumnos fue reconocida por el Consejo Superior de la Universidad Nacional de La Plata al nombrarlo Profesor Extraordinario en categoría Consulto por sus méritos en docencia. Se destaca además, que dentro de los reconocimientos científicos le fueron dedicadas dos especies: Piper sotae Yunck. y Lycopodium sotae Rolleri.

Su entusiasmo por la investigación quedó impreso en aproximadamente 120 publicaciones, y una de ellas, la Flora de Jujuy ${ }^{2}$, se convirtió en la referencia obligada para el estudio de los helechos y licófitos del norte de Argentina. Finalmente sus líneas de investigación y filosofía científica se sintetizan muy adecuadamente en el preámbulo de su curriculum vitae que se transcribe a continuación:

"Traté de estimular el desarrollo de los estudios en helechos y grupos emparentados, conformando un conjunto de discípulos muy activos y que se hallan ubicados en diferentes partes del país y del extranjero, como Ciudad Autónoma de Buenos Aires, Buenos Aires, Córdoba,

${ }^{1}$ Tesis doctoral publicada: Sota, E. R. de la. 1960. Polypodiaceae y Grammitidaceae Argentinas. Opera Lilloana 5: $1-229$.

${ }^{2}$ Sota, E. R. de la . 1977. Pteridophyta. En: A. Cabrera (dir.), Flora de Jujuy. Colecc. Ci. Inst. Nac. Tecnol. Agropecu. 13: $1-275$. 
Corrientes, Jujuy, Salta, Tucumán, Chile. Puse preferencia en el Neotrópico, poniendo particular énfasis en su morfología comparada e intermedia, homologías de posición, homofilias hipotéticas, paralelismos, dimorfismo foliar, nerviación, alimentación de las áreas receptaculares, conexiones, rutas migratorias y estaciones intermedias en la temática biogeográfica. Usando esas evidencias he tratado de interpretar el origen y desarrollo de la biodiversidad florística en el Cono Sur de América. Continúo aportando datos para estructurar los tres centros de diversificación en el Cono Sur y las relaciones entre Brasil austral, los bosques andino-patagónicos y el arco peripampásico. Presto particular atención al epifitismo y dimorfismo foliar, procurando el encuentro de biomonitores ambientales adecuados para fijar pautas de contaminación ambiental y alteraciones, sobre la base de pelos y escamas de penetración en el mesófilo, tipo "tilandsioide". En resumen, uso los helechos y grupos emparentados como conjuntos "piloto" en esos procesos. Me considero ubicado dentro de la teoría "filomista", contraria a la teoría telomista, apoyando la postura de que la forma condiciona la estructura y que filogenéticamente la secuencia de los órganos fue expansión laminar-raíz-eje caulinar." 